\title{
Mitochondria Dynamically Transplant into Cells in Vitro and in Mice and Rescue Aerobic Respiration of Mitochondrial DNA-Depleted Motor Neuron NSC-34
}

\author{
Xian-Peng Jiang ${ }^{1}$, Catherine C. Baucom², Robert L. Elliott ${ }^{1,2}$

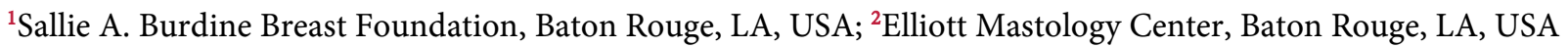 \\ Correspondence to: Xian-Peng Jiang, jiang@breastoncology.com \\ Keywords: Mitochondrial Transplantation, Motor Neuron, Mitochondria, Neurodegenerative Disease, Mammary \\ Adenocarcinoma, Mitochondrial DNA Depletion, Fibroblast, HLA-I, NSC-34 Cells
}

Received: August 20, $2020 \quad$ Accepted: September 25, $2020 \quad$ Published: September 28, 2020

Copyright $\odot 2020$ by author(s) and Scientific Research Publishing Inc.

This work is licensed under the Creative Commons Attribution International License (CC BY 4.0).

http://creativecommons.org/licenses/by/4.0/

\section{(c) (i) Open Access}

\section{ABSTRACT}

It has been reported that transplantation of pheochromocytoma P12 and hepatoma cells' mitochondria improve the locomotive activity and prevent disease progress in experimental Parkinson's disease rats. To prepare for mitochondrial transplantation study in human neurodegenerative diseases, we select human fibroblasts as mitochondrial donor because that fibroblasts share many characteristics with mesenchymal stromal cells (MSCs). We isolate human primary fibroblasts and develop a mitochondrial DNA (mtDNA)-depleted mouse motor neuron NSC-34 cells (NSC-34 $\rho^{\circ}$ cells). Fibroblast and NSC-34 cell's mitochondria are co-cultured with NSC-34 $\rho^{\circ}$ cells. Mitochondrial transplantation is observed by fluorescent microscopy. Gene expression is determined by polymerase chain reaction (PCR) and real time PCR (qPCR). Also, mitochondria are injected to mice bearing mammary adenocarcinoma 4T1 cells. We find results as following: 1) There are abundant mitochondria in fibroblasts $(337 \pm 80$ mitochondria per fibroblast). $42.4 \%$ of viable mitochondria are obtained by using differential centrifugation. The isolated mitochondria actively transplant into NSC-34 $\rho^{\circ}$ cells after co-culture. 2) Fibroblasts transfer mitochondria to human mammary adenocarcinoma MCF-7 cells. 3) There is no expression of HLA-I antigen in fibroblast's mitochondria indicating they can be used for allogeneic mitochondrial transplantation without HLA antigen match. 4) PCR and GPCR show that NSC-34 $\rho^{\circ}$ cells lose mitochondrially encoded cytochrome c oxidase I (MT-CO1) and mitochondrially encoded NADH dehydrogenase 1 (MT-ND1) and upregulate expression of glycolysis-associated genes hexokinase (HK2), glucose transporter 1 (SLC2A1) and lactate dehydrogenase A (LDHA). 5) Transplantation of NSC-34 mitochondria restores MT-CO1 and MT-ND1 and downregulates gene expression of HK2, SLC2A1 and LDHA. 6) Normal mammary epithelial mitochondria 


\begin{abstract}
successfully enter to 4T1 cells in mice. Subcutaneous injection of mitochondria is safe for mice. In summary, mitochondrial transplantation replenishes mtDNA and rescues aerobic respiration of diseased cells with mitochondrial dysfunction. Human primary fibroblasts are potential mitochondrial donor for mitochondrial transplantation study in human neurodegenerative diseases.
\end{abstract}

\title{
1. INTRODUCTION
}

In eukaryotic cells, mitochondria are well known as the powerhouse who generates ATP by oxidative phosphorylation (OXPHOS) in the presence of oxygen. They also play an important role in synthesis of iron-sulfur (Fe-S) clusters, $\beta$-oxidation of fatty acids, synthesis of heme prosthetic groups, the urea cycle, as well as homeostasis of calcium, iron and reactive oxygen species (ROS) [1-3]. Mitochondria are highly dynamic organelles which frequently fuse and divide. Mitochondrial fusion/fission allow segregation of damaged mitochondria, mitophagy to remove damaged mitochondria, and ultimately cell death if the damage is too severe $[4,5]$. In addition, mitochondria can transfer between cells. Cells may be able to obtain functional mitochondria from other cells in order to satisfy their bioenergetics and biosynthetic needs. The possible mechanisms include tunneling nanotubes, extracellular vesicles and partial or complete cell fusion $[3,6-9]$.

Mitochondrial dysfunction contributes to many diseases such as neurodegenerative disease, cardiac disease and cancer. Mitochondrial dysfunction has been well documented in amyotrophic lateral sclerosis (ALS), Alzheimer's disease (AD) and Parkinson's disease (PD) [10-15]. Mitochondria are essential for neural function because neurons highly depend on aerobic OXPHOS in mitochondria for their energetic needs. Defective mitochondrial respiration and ATP production in neurons result in neural dysfunction and degeneration. Mitochondria also produce ROS. If oxidative stress of ROS overwhelms the antioxidative defense most from superoxide dismutase (SOD), catalase (CAT) and glutathione peroxidase (GPX), ROS causes protein, lipid and DNA damage of neurons. In addition, overload of mitochondrial calcium and iron impairs ATP production and structures of mitochondria and neurons [15, 16]. A few proteins from gene mutations have been linked to familial and sporadic ALS, including superoxide dismutase 1 (SOD1), TAR DNA binding protein (TARDBP; TDP-43), Fused in sarcoma (FUS), Chromosome 9 open reading frame 72 (C9orf72) and dipeptide repeat protein (DPR), have been shown to interact with mitochondria in ALS mouse models and human patients [10,17].

Mitochondria are highly present in cardiac cells due to the increased energy demands. Mitochondrial dysfunction is associated with the development of numerous cardiac diseases such as atherosclerosis, ischemia-reperfusion injury, hypertension, cardiac hypertrophy and heart failure [18].

Otto Warburg described defects in mitochondrial function were linked to tumorigenesis. He observed that cancer cells had increase in glycolysis and lactate production in the presence of oxygen without an increase in OXPHOS, known as the "Warburg Effect" [19]. Many cancers have mitochondrial defects and dysfunction [20,21]. Glycolytic inhibitors have been reported to suppress tumor growth in animal models and clinical trials $[22,23]$.

It has been shown that free mitochondria isolated from cells and tissues are integrated into other cells especially diseased cells such as mitochondrial DNA (mtDNA)-depleted cells [24], ischemic cardiac cells in animals [25, 26], injured spinal cord in animals [27] and cancer cells [21, 28]. Moreover, exogenous healthy mitochondria could rescue aerobic respiration of diseased cells. Chang JC et al. reported that allogeneic and xenogeneic transplantation of peptide-labeled mitochondria after 3 months improved the locomotive activity in the PD rats [29].

In the present study, we examine normal mitochondrial transplantation (MT) to defective neurons and tumor cells in cell culture and mice, and safety of mitochondrial injection in mice. We find that mitochondria transfer between human fibroblasts and breast cancer cells after co-culture. Mitochondria isolated from human fibroblasts could transplant to mouse mtDNA-depleted neurons. Transplantation of mouse motor neural mitochondria replenishes mtDNA and rescues aerobic respiration of mouse 
mtDNA-depleted neurons. In addition, mitochondria isolated from mouse normal mammary epithelia are integrated into mammary adenocarcinoma cells in mouse model. Injection of exogenous mitochondria is safe for experimental mice.

\section{MATERIALS AND METHODS}

\subsection{Isolation, Primary Culture and Cryopreservation of Human Fibroblasts}

All protocols use sterile techniques in a Class II, Type A2 laminar flow hood. All culture plastic materials and surgical scalpel are sterile and disposal. Human skin tissue was donated by a young healthy man who signed informed consent. Skin tissue was surgically collected in outpatient clinical center and dropped to a $50 \mathrm{ml}$ disposal sterile centrifuge tube containing $15 \mathrm{ml}$ of sterile $0.9 \%$ sodium chloride injection. Skin $(0.5 \mathrm{~cm} \times 2 \mathrm{~cm})$ was washed with cold sterile saline. Fat tissue was trimmed. The skin was cut to small pieces using a sterile disposal scalpel in a sterile disposal $100 \mathrm{~mm}$ culture dish. All tissue pieces and saline were transferred into a sterile glass chamber with cap and stir bar. $4.5 \mathrm{ml}$ of $3 \%$ collagenase type 3 (Worthington Biochemical Corporation, Lakewood, NJ, USA) was added to the chamber. The final volume was $20 \mathrm{ml}$. The chamber was placed on a magnetic stirrer at speed $150 \mathrm{rpm}$ in $37^{\circ} \mathrm{C}$ oven for digestion. The tissue was digested for 5 hours with gentle stirring till tissue piece disappear. The liquid was transferred into a sterile $50 \mathrm{ml}$ centrifuge tube and centrifuged for 5 minutes at $400 \mathrm{~g}$. Aspirate the supernatant. Add $20 \mathrm{ml}$ pre-warmed $\left(37^{\circ} \mathrm{C}\right)$ complete alpha minimum essential media (alpha MEM) (GIBCO, Carlsbad, CA, USA) containing 5\% human platelet lysate (HPL) (Biological Industries, Cromwell, CT, USA) and $0.05 \mathrm{mg} / \mathrm{ml}$ gentamicin (GIBCO, Carlsbad, CA, USA). Re-suspend cell pellet and transfer cell suspension to a $182 \mathrm{~cm}^{2}$-flask. The flask was cultured at $37^{\circ} \mathrm{C}$ with $5 \% \mathrm{CO}_{2}$ incubator overnight. The medium and floating cells was aspirated next day. $20 \mathrm{ml}$ fresh medium was added to the flask. The flask was returned to the incubator for culture with medium refresh every 3 - 4 days. When cells growth was $80 \%$ confluent, cells were sub-cultured to new flasks by 1:10 dilution. The primary fibroblasts of second and third passages were collected, re-suspended in Nutrifreez D10 cryopreservation medium (Biological Industries, Cromwell, CT, USA), aliquoted to $1 \mathrm{ml}$ containing $1 \times 10^{6}$ cells in cryovials, frozen and stored in liquid nitrogen.

\subsection{Cell Cultures}

Human mammary adenocarcinoma cell line MCF-7, mouse mammary adenocarcinoma cell line 4T1 and mouse mammary epithelium cell line EpH4-Ev were purchased from American Type Culture Collection (ATCC) (Manassas, VA, USA). MCF-7, 4T1 and human primary fibroblasts were recovered from liquid nitrogen and cultured in alpha MEM containing $10 \%$ fetal bovine serum (FBS) (GIBCO, Carlsbad, CA, USA). EpH4-Ev cells were culture in alpha MEM containing $10 \%$ FBS and $1.2 \mu \mathrm{g} / \mathrm{mL}$ puromycin (Sigma Aldrich, St. Louis, MO, USA). NSC-34 is a hybrid cell line, produced by fusion of motor neuron enriched, embryonic mouse spinal cord cells with mouse neuroblastoma. NSC-34 was purchased from Cedarlane corporation (Ontario, Canada) and cultured in Dulbecco's modified eagle medium (DMEM) (GIBCO, Carlsbad, CA, USA) containing 10\% FBS. When cells grew to 80\% full in flask, they were digested with TrypLE expression solution (GIBCO, Carlsbad, CA, USA) and sub-cultured at $37^{\circ} \mathrm{C}$ and $5 \% \mathrm{CO}_{2}$.

\subsection{Isolation of Mitochondria}

Mitochondrial were isolated by differential centrifugation following a previously described protocol [30-32]. All reagents were sterile. Cells were harvested with TrypLe expression solution and pelleted by centrifugation for 5 minutes at $400 \times \mathrm{g}$ and at $4^{\circ} \mathrm{C}$. After aspiration of the solution and media, cell pellet was re-suspended in ice-cold $300 \mathrm{mM}$ sucrose mitochondrial isolation buffer (MIB) (Sigma Aldrich, St. Louis, MO, USA) and homogenized by bead beating (Bead Ruptor 12, Omni International homogenizer company (Kennesaw, GA, USA). The cell lysate was centrifuged for 10 minutes at $700 \times \mathrm{g}$ and at $4^{\circ} \mathrm{C}$. Then 
the supernatant was transferred to new centrifugation tubes and centrifuged for 10 minutes at $9000 \times \mathrm{g}$ and at $4^{\circ} \mathrm{C}$. The supernatant was removed. The mitochondrial pellet was re-suspended with $240 \mathrm{mM}$ sucrose mitochondrial respiration buffer (MRB) (Sigma Aldrich, St. Louis, MO, USA). In order to determine the number of isolated mitochondria, $10 \mu \mathrm{l}$ of JC-1-stained mitochondria was placed on glass slide and covered with $22 \mathrm{~mm} \times 22 \mathrm{~mm}$ coverslip (area $4.84 \times 10^{8} \mu \mathrm{m}^{2}$ ). The mitochondria were observed through 20x object lens, taken photo pictures in five fields and counted mitochondrial number each picture by Cellsense software of Olympus IX83 fluorescent microscope (Olympus, Tokyo, Japan). Object area each picture was calculated by using the scale bar $(\mu \mathrm{m})$ in the pictures. Number of mitochondria in $10 \mu \mathrm{l}$ was calculated as the following: (coverslip area $4.84 \times 10^{8} \mu \mathrm{m}^{2} \div$ object area in $\mu \mathrm{m}^{2}$ per picture) $\times$ the average of mitochondrial number per picture. Then total isolated mitochondria number was calculated [30, 33].

\subsection{Measurement of Mitochondrial Protein}

Mitochondrial protein content can be used to estimate mitochondrial number [33]. The mitochondrial pellets were lysed by RIPA buffer (Thermofisher Scientific, Waltham, MA, USA). The mitochondria were shaken gently for 30 minutes on ice. Then the mitochondrial lysate was centrifuged at $14,000 \times \mathrm{g}$ for 10 minutes to pellet debris. The supernatant was transferred to $1.5 \mathrm{ml}$ vial for protein content measurement. The protein was quantitated by Pierce BCA protein assay kit (Thermo Scientific, Rockford, IL, USA). The procedure is seen in the protocol of the assay kit. In brief, pipette $25 \mu$ of standard or sample to the replicate wells, add $200 \mu \mathrm{l}$ of BCR working reagent to each well and mix plate thoroughly for 30 seconds, incubate the plate at $37^{\circ} \mathrm{C}$ for 30 minutes, cool down the plate to room temperature, and measure the absorbance at $562 \mathrm{~nm}$ on a plate reader. The protein concentrations of samples were calculated by four-parameter logistic curve.

\subsection{Immunofluorescent Staining of Human Leukocyte Antigen I (HLA I) in Primary Fibroblasts and Mitochondria}

20,000 primary fibroblasts were cultured at glass bottom cell culture dishes overnight. Mitochondria were isolated from $5 \times 10^{6}$ fibroblasts. fibroblasts in dishes and the mitochondria in $1.5 \mathrm{ml}$ Eppendorf centrifugation tubes were fixed with $4 \%$ paraformaldehyde solution for 15 minutes at room temperature. The rabbit anti-human HLA-ABC polyclonal antibody (Thermofisher Scientific, Waltham, MA, USA) reacts to all types (HLA-A, -B and -C) of HLA I antigen. The brief procedure of immunofluorescent staining is as following: wash twice with $1 \mathrm{x}$ phosphate buffered saline (PBS), block with $5 \%$ goat serum in $1 \times$ PBS, wash once, incubate with $200 \mu \mathrm{l}$ 1:400 dilution of rabbit anti-human HLA-ABC polyclonal antibody overnight at $4^{\circ} \mathrm{C}$, wash 3 times with $1 \times \mathrm{PBS}$, incubate with goat anti-rabbit IgG-Alexa 488 for 1 hour at room temperature, wash for 3 times with $1 \times$ PBS, add $300 \mu \mathrm{l}$ of $1 \times$ PBS to the dishes and tubes, re-suspend the mitochondria in $1.5 \mathrm{ml}$ Eppendorf tubes and add $100 \mu \mathrm{l}$ of the mitochondria to the glass area of new glass bottom dishes, observe fluorescence under Olympus IX83 fluorescent microscope. All pictures were taken with 1 second exposure.

\subsection{Staining Mitochondria with JC-1 or MitoTracker Dyes}

Mitochondrial membrane potential generated by proton pumps is an essential component in the process of energy storage during OXPHOS. Membrane potential dependent dyes such as JC-1(5,5',6,6'tetrachloro-1,1',3,3'-tetraethylbenzimidazolocarbocyanine iodide) and MitoTracker dyes (rosamine- or cyCarbocyanine-based probes) have been used to stain mitochondria and monitor mitochondrial potential. For JC-1 staining, mitochondria were stained with mitochondria staining kit (Sigma CS0390, St. Louis, MO, USA). The brief procedure is as follows: Mix $25 \mu \mathrm{l}$ of $200 \times \mathrm{JC}-1$ Stock Solution in $4 \mathrm{~mL}$ of ultrapure water in a test tube. Close the test tube and mix solution by inversion or vortex test tube briefly. Incubate test tube for $2 \mathrm{~min}$ at room temperature to completely dissolve JC-1. Open the test tube and add $1 \mathrm{ml}$ of JC-1 Staining Buffer $5 \times$. Mix by inversion. Then, mix the staining mixture with an equal volume of complete medium for cell growth. Aspirate growth medium from flask and overlay cells with the above 
mixture. Add $0.2-0.4 \mathrm{ml}$ of the mixture per $\mathrm{cm}^{2}$ of growth surface. Incubate cells for 20 minutes at $37^{\circ} \mathrm{C}$ in humidified atmosphere containing $5 \% \mathrm{CO}_{2}$. Aspirate the mixture. Wash the cells twice with cold growth medium. Fluorescence is observed by Olympus IX83 fluorescent microscope. In cells which maintain electrochemical potential gradient, the dye concentrates in mitochondria, where it forms bright red fluorescent aggregates (J-aggregates). If cells failed to maintain membrane potential, the JC-1 is dispersed through the entire cells resulting in a shift from red to green fluorescence (JC-1 monomers).

For MitoTracker dyes, culture media were aspirated. Cells were covered with fresh media containing $150 \mathrm{nM}$ of MitoTracker Orange or Red dyes (Thermofisher Scientific, Waltham, MA, USA).and cultured for 30 minutes at $37^{\circ} \mathrm{C}$ and $5 \% \mathrm{CO}_{2}$. Then, staining solution was removed. Cells were washed once, covered with fresh media, and observed under fluorescent microscope.

\subsection{Mitochondrial Transfer between Fibroblasts and Cancer MCF-7 Cells}

CellLight Mitochondria-RFP or -GFP, BacMam 2.0 were purchased from Invitrogen (Carlsbad, CA, USA). They are fluorescent and the leader sequence of $\mathrm{E} 1$ alpha pyruvate dehydrogenase (in mitochondrial matrix) fusions that provide accurate and specific targeting to mitochondria in live-cell mitochondrial imaging. Cells grew on culture dishes to $70 \%$ confluence. The appropriate volume of CellLight reagent for the number of cells were calculated as the protocol of the products. The volume of CellLight mitochondria-RFP or -GFP were added to cells. The cells were incubated at $37^{\circ} \mathrm{C}$ at least 16 hours and observed by Olympus IX83 fluorescent microscope. Averaged number of mitochondria per fibroblast was determined by Cellsense software. In order to test mitochondrial transfer between adenocarcinoma cell MCF-7 and fibroblasts, mitochondria of MCF-7 and fibroblasts were labelled with CellLight Mitochondria-RFP or -GFP, respectively, for at least 16 hours. The media were removed. Cells were washed twice with prewarmed fresh media and dis-attached with TrypLE express reagent. Same number of MCF-7 and fibroblasts were mixed and co-cultured at $37^{\circ} \mathrm{C}$ and $5 \% \mathrm{CO}_{2}$ for 24 hours. The fluorescence in cells was observed by Olympus IX83 fluorescent microscope.

\subsection{Depleting Mitochondrial DNA of NSC-34 by Ethidium Bromide}

It has been reported that long-term treatment of cells with low doses $(0.1-2 \mu \mathrm{g} / \mathrm{ml})$ of ethidium bromide $(\mathrm{EtBr})$, an inhibitor of DNA/RNA synthesis, specifically suppresses the replication and transcription of extrachromosomal genetic components such as mtDNA without affecting nuclear DNA replication and transcription [34]. NSC-34 cells were maintained in the complete DMEM medium containing $2 \mu \mathrm{g} / \mathrm{ml} \mathrm{EtBr}$ and sub-cultured every week with medium refresh every 3 - 4 days. After 3 months, total DNA of NSC-34 was isolated with QIAamp DNA mini kit (Qiagen, Hilden, Germany). MT-CO1 and MT-ND1 were tested by PCR. PCR was performed in a total $25 \mu \mathrm{l}$ volume including $2 \mu \mathrm{l}$ of PCR Master mix (Thermofisher Scientific, Waltham, MA, USA), $0.5 \mu \mathrm{l}$ of $100 \mu \mathrm{M}$ forward and reverse primers and 200 ng DNA template. The primers used for amplification of MT-CO1 were

5'-CTAGCCGCAGGCATTACTATAC-3' and 5'-TGTCAAGGGATGAGTTGGATAAA-3'. The primers for MT-ND1 were 5'-GCCGTAGCCCAAACAATTTC-3' and 5'-CGTAACGGAAGCGTGGATAA-3'. Mouse $\beta$-actin (ACTB) was used as endogenous gene control. The primers for ACTB amplification were 5'-CTGAGTCTCCCTTGGATCTTTG-3' and 5'-AGGGCAGGTGAAACTGTATG-3'. The amplification procedure included initial DNA denaturing at $95^{\circ} \mathrm{C}$ for 3 minutes, then 35 cycles of denaturing 30 seconds at $95^{\circ} \mathrm{C}$, primer annealing 30 seconds at $50^{\circ} \mathrm{C}$ and 60 seconds of extension at $72^{\circ} \mathrm{C}$, and final extension of 10 minutes at $72^{\circ} \mathrm{C}$ in a T100 Thermal Cycle (Bio-Rad, Hercules, CA, USA). PCR products were run on a $2 \%$ agarose gel and imaged by ethidium bromide fluorescence.

\subsection{Mitochondrial Transplantation to mtDNA-Depleted NSC-34 (NSC-34 $\rho^{\circ}$ )}

Mitochondria were isolated from mouse NSC-34 cells. The mitochondria (from $1 \times 10^{6}$ cells) were co-cultured with $1 \times 10^{5} \mathrm{NSC}-34 \rho^{\circ}$ cells (Mitochondria from 10 NSC-34 cells +1 NSC-34 $\rho^{\circ}$ cell). Normal 
NSC-34 was as control. After 24 hours of co-culture, the media containing the mitochondria were removed. Cells were washed twice, refilled with fresh complete DMEM, and continuously cultured. DNA and RNA of cells were isolated at 1, 3 and 6 days, respectively, after transplantation for PCR and real time PCR examination. For imaging of mitochondrial transplantation, mitochondria of NSC-34 cells and primary fibroblasts were labelled with MitoTracker Red, isolated and co-cultured with NSC-34 $\rho^{\circ}$ cells for 24 hours (Mitochondria from 10 NSC-34 cells or fibroblasts +1 NSC-34 $\rho^{\circ}$ cell). After removal of the media containing the labelled mitochondria, cells were observed under fluorescent microscope.

\subsection{Real Time PCR (qPCR)}

We used qPCR to measure mRNA levels of mitochondrial and glycolysis-associated genes. The detailed protocol was published previously [28]. We examined mitochondrial OXPHOS genes, MT-CO1 and MT-ND1, and glycolysis-associated genes HK2, SLC2A1 and LDHA which catalyzed the reduction of pyruvate by $\mathrm{NADH}$ to form lactate. All gene expression quantification was performed with TaqMan Gene Expression Assay, a proven 5' nuclease-based real-time PCR chemistry. Primers and probes (PrimeTime Mini qPCR assay) were synthesized by Integrated DNA Technologies (IDT, Coralville, Iowa) (Table 1). $\beta$-actin (ACTB) was used as endogenous gene control to normalized PCRs for the amount of RNA added to the reverse transcription reactions. Probes contain at the 5' end the FAM (6-carboxy fluorescein) as a fluorescent reporter dye, and internal and at 3' end the $\mathrm{ZEN}{ }^{\mathrm{TM}} /$ Iowa Black FQ as fluorescent double quenchers. The qPCR reaction was performed with $7900 \mathrm{HT}$ real time PCR system (Applied Biosystems, Grand Island, NY). Standard mode ran as 2 minutes at $50^{\circ} \mathrm{C}$ and 10 minutes at $95^{\circ} \mathrm{C}$, and 40 cycles $[15$ seconds at $95^{\circ} \mathrm{C}$ (denaturing) and 1 minute at $60^{\circ} \mathrm{C}$ (annealing/extending)]. Target gene expression was determined by relative quantification which related signal of the target transcript in an experimented group to that of a control. We analyzed relative quantification with the RQ Manager 1.2.1 software (Applied Biosystems, Grand Island, NY, USA).

Table 1. List of primer and probe sequences for qPCR.

\begin{tabular}{lll}
\hline Gene & Pair of primers (FWD and REV) & Probe \\
\hline ACTB & GAGGTATCCTGACCCTGAAGTA; & TGGCATTGTTACCAACTGGGACGA \\
MT-CO1 & CACACGCAGCTCATTGTAGA & \\
& CTCCTCCATCATTTCTCCTTCTC; & AAGCAGGAGCAGGAACAGGATGAA \\
MT-ND1 & CCATTTGCAGACGCCATAAA; & AGAACCAATACGCCCTTTAACAACC \\
& GAGTGATAGGGTAGGTGCAATAA & \\
HK2 & TCAAAGAGAACAAGGGCGAG; & AGAAACATCCCCATTTTGCCAAGCG \\
& AGGAAGCGGACATCACAATC & \\
SLC2A1 & GATTGGTTCCTTCTCTGTCGG; & TTATGGGCTTCTCCAAACTGGGCA \\
& CCCAGGATCAGCATCTCAAAG & \\
LDHA & GCTCCCCAGAACAAGATTACAG; & AGCTCATCCGCCAAGTCCTTCATT \\
& TCGCCCTTGAGTTTGTCTTC &
\end{tabular}




\subsection{Mitochondrial Transplantation to Mammary Adenocarcinoma 4T1 Cells in Mouse}

The Institutional Animal Care and Use Committee (IACUC) protocol was submitted and approved by Louisiana State University School of Veterinary Medicine. Female mice were 16 - 18 grams (average $17.3 \mathrm{~g}$ ) and 8 weeks old. $1 \times 10^{5}$ mouse mammary adenocarcinoma $4 \mathrm{~T} 1$ cells in $0.2 \mathrm{ml} 0.9 \% \mathrm{NaCl}$ was injected subcutaneously into each mouse. When tumor grew to $1 \mathrm{~cm}$ diameter, $0.2 \mathrm{ml}$ of isolated mitochondria $\left(5 \times 10^{7}\right.$ mitochondria) from $1.0 \times 10^{6} \mathrm{EpH} 4-\mathrm{Ev}$ cells were directly injected into tumor. The mitochondria of normal epithelial EpH4-Ev were pre-labelled with MitoTracker orange dye, isolated and stored in MRB on ice. After 24 hours, tumor was biopsied and smeared on glass slides. Tumor smearing slides were observed under fluorescent microscope to check whether the labeled mitochondria entered into $4 \mathrm{~T} 1$ tumor cells. To examine inhibition of normal mitochondria to tumor cells, mixture of $1 \times 10^{5} 4 \mathrm{~T} 1$ and mitochondria $\left(5 \times 10^{7}\right.$ mitochondria) cells in $0.2 \mathrm{ml}$ of MRB was injected subcutaneously into the dorsal cervical area of mouse ( 1 tumor $4 \mathrm{~T} 1$ cell + mitochondria from $10 \mathrm{EpH} 4-\mathrm{Ev}$ cells). Control group mice were only injected with $1 \times 10^{5} 4 \mathrm{~T} 1$ cells in $0.2 \mathrm{ml}$ of MRB per mouse. Control group and mitochondria-treated group have10 and 11 mice, respectively. At 18 days post-injection, mice were sacrificed and necropsied. Tumor mass and organs including lungs, liver, heart, spleen, and kidneys were removed and weighed. All tissues were fixed in $4 \%$ formalin solution for histological study.

\subsection{Statistical Analysis}

Student's t-test was used to test statistical significance. p-value less than 0.05 was judged to be of statistical significance.

\section{RESULTS}

\subsection{Number, Protein Content and Viability of Isolated Mitochondria}

The life span of the human primary fibroblasts is approximate 80 days. The double time of growth is $40 \pm 6$ hours. We labelled mitochondria of fibroblasts with CellLight Mitochondria-GFP and counted number of mitochondria per fibroblast in 30 different fields by Cellsense software of Olympus IX83 fluorescent microscope. There are mitochondria of $337 \pm 80$ (mean \pm standard deviation) per human fibroblast (Figure 1). Mitochondrial viability is rapidly and easily assessed using mitochondrial fluorescent probes $[24,25,33]$. We find that the isolated mitochondria actively concentrate JC-1 and form bright red fluorescent aggregates (J-aggregates) (Figure 2). This finding suggests that the isolated mitochondria are viable and maintain electrochemical potential gradient. Total $(1.43 \pm 0.33) \times 10^{9}$ of mitochondria could be isolated from $1 \times 10^{7}$ fibroblasts which totally have $(3.37 \pm 0.8) \times 10^{9}$ mitochondria in cells. The mitochondrial isolation protocol can obtain $42.4 \%\left[\left(1.41 \times 10^{9}\right) \div\left(3.37 \times 10^{9}\right)\right.$ $\times 100 \%]$ of fibroblast mitochondria. Mitochondrial protein content is an alternative method to estimate mitochondrial number [33]. The $(1.43 \pm 0.33) \times 10^{9}$ of mitochondria that isolated from $1 \times 10^{7}$ fibroblasts have $190 \pm 45 \mu \mathrm{g}$ protein content. Both the fibroblast number and mitochondrial protein content can estimate number of isolated mitochondria.

\subsection{Fibroblast's Mitochondria Don't Express HLA-I Antigen}

Green fluorescence is found on cell surface of human fibroblasts. The distribution of green fluorescence is uneven (Figure 3(b)). The finding suggests HLA class I antigens mainly express on cell surface of human fibroblasts. The isolated mitochondria have no green fluorescent staining (Figure 3(d)). These results suggest that mitochondria of human fibroblasts don't express HLA antigens and may be used for allogeneic mitochondrial transplantation without HLA antigen match.

\subsection{Mitochondria Transfer between Human Fibroblasts and Mammary Adenocarcinoma MCF-7}

CellLight Mitochondria-GFP-labelled fibroblasts were co-cultured with CellLight Mitochondria-RFP- 
labelled MCF-7 for 24 hours. Mitochondria moving between fibroblasts (green) and MCF-7 cells (red) result in orange fluorescence in some cells (arrow in Figure 4).

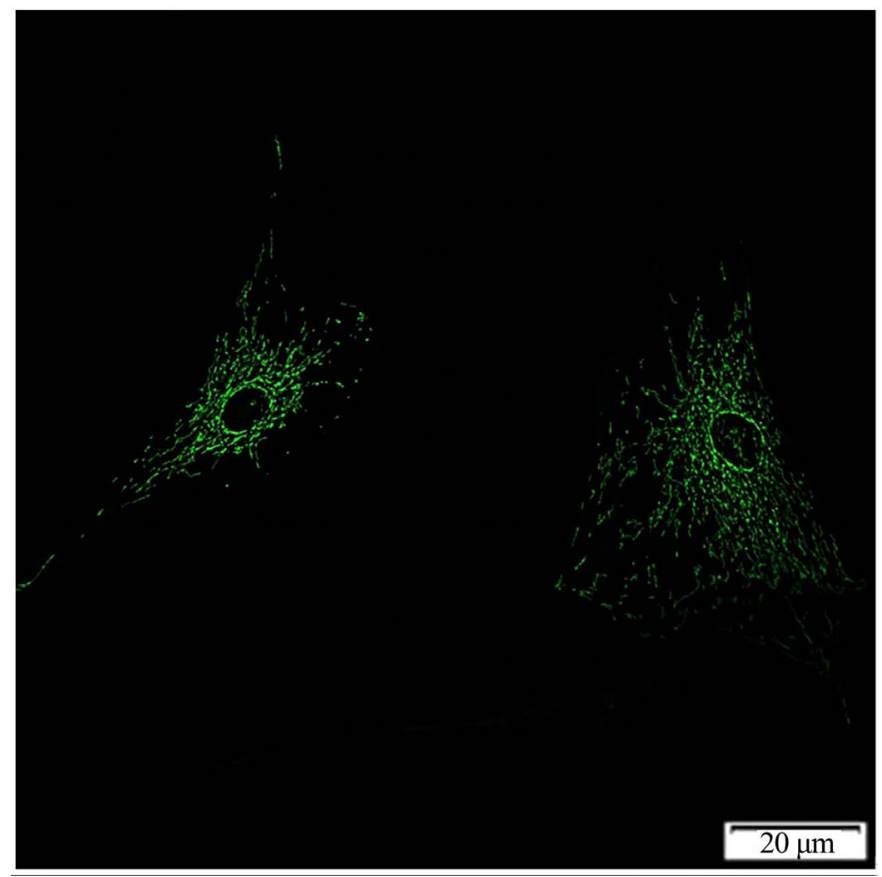

Figure 1. GFP-labelled mitochondria of fibroblasts $(40 x)$. There are $337 \pm 80$ mitochondria per human fibroblast. Mitochondria were counted and analyzed by Olympus IX83 fluorescent microscope and Cellsense software. (Details in Materials and Methods)

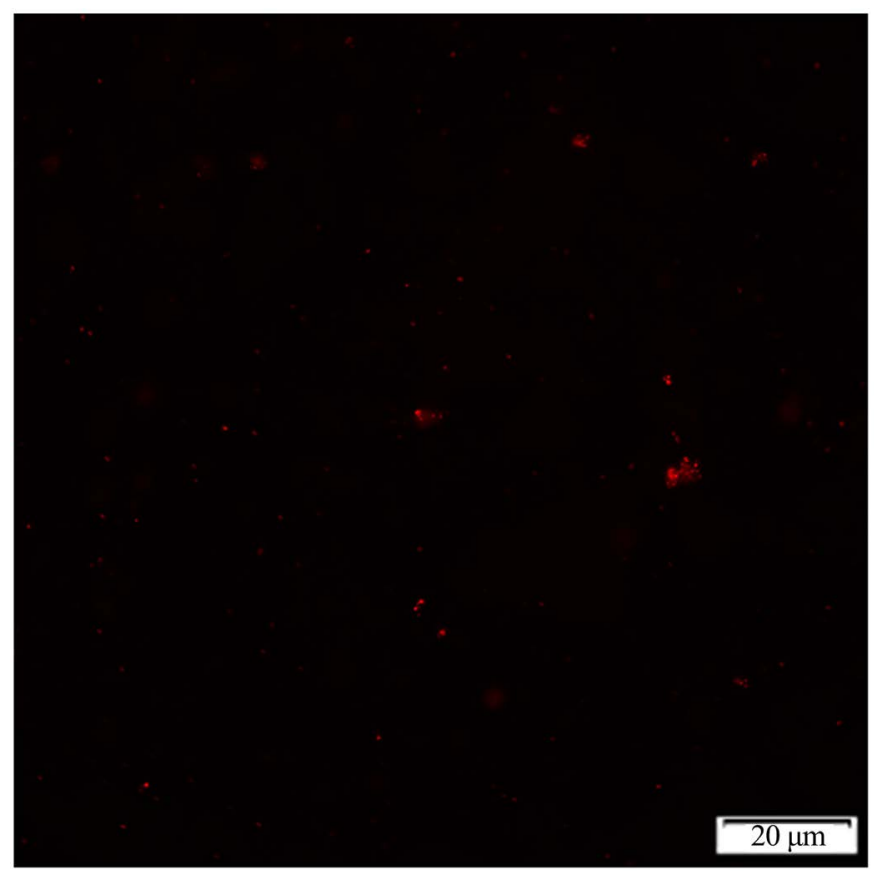

Figure 2. Viable mitochondria isolated from fibroblasts. The mitochondria maintain membrane potential gradient, actively concentrate JC-1 and form bright red fluorescent aggregates (J-aggregates). 

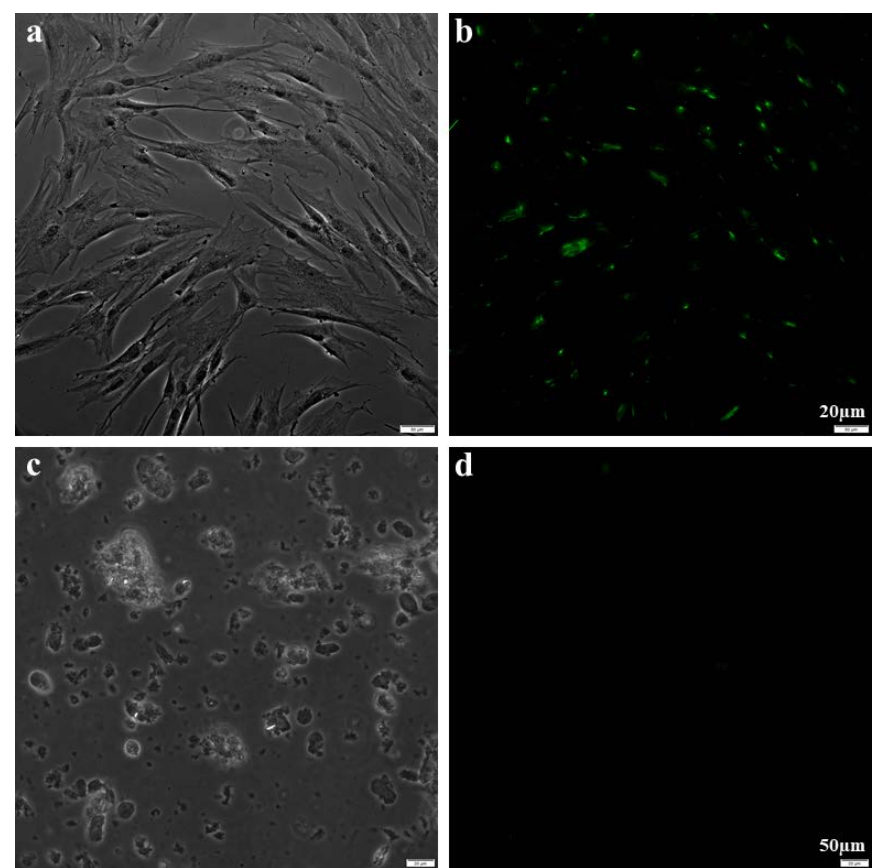

Figure 3. Immune fluorescent staining of HLA-I antigen. Green fluorescent staining on cell surface of fibroblasts (b) but no positive staining in isolated mitochondria (d). (a), (c) phase contrast; (b), (d) fluorescence; (a), (b) fibroblasts; (c), (d) isolated mitochondria from fibroblasts.

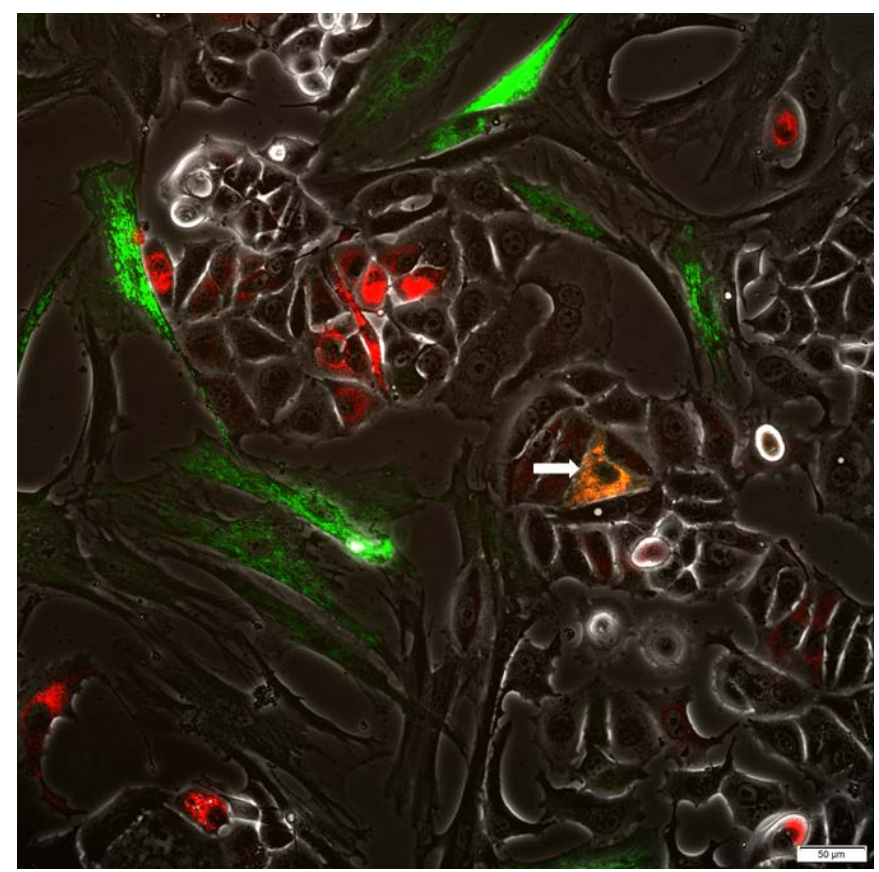

Figure 4. Fibroblasts transfer mitochondria to MCF-7 cancer cells. The cell, pointed by arrow, has mitochondria from both fibroblast (mitochondria with green fluorescence) and MCF-7 (mitochondria with red fluorescence). Thus, the mitochondria (combination of green and red) show orange fluorescence. (Details in Materials and Methods). 


\subsection{Normal Mitochondria Transplant to NSC-34 $\rho^{\circ}$ Cells}

After treatment of NSC-34 with $2 \mu \mathrm{g} / \mathrm{ml} \mathrm{EtBr}$ for 3 months, PCR shows there is no amplification of mitochondrial genes MT-CO1(490 bp) and MT-ND1(445 bp). The treatment has no effect on genomic gene ACTB amplification (298 bp) (Figure 5). The results suggest long term of EtBr-treatment depleted mtDNA of NSC-34 cells. NSC-34 $\rho^{\circ}$ cells grow much slower than parent NSC-34. The growth of NSC-34 $\rho^{\circ}$ cells is approximate $10 \%$ of parent NSC-34. Isolated MitoTracker red-labelled mitochondria from NSC-34 cells or primary fibroblasts were co-cultured with NSC-34 $\rho^{\circ}$ cells. At 24 hours post-culture, mitochondria with red fluorescence are observed in NSC-34 $\rho^{\circ}$ cells (Figure 6(a), Figure 6(b)). These results suggest that isolated autologous and xenogeneic mitochondria transplant to the defective NSC-34 $\rho^{\circ}$ cells.

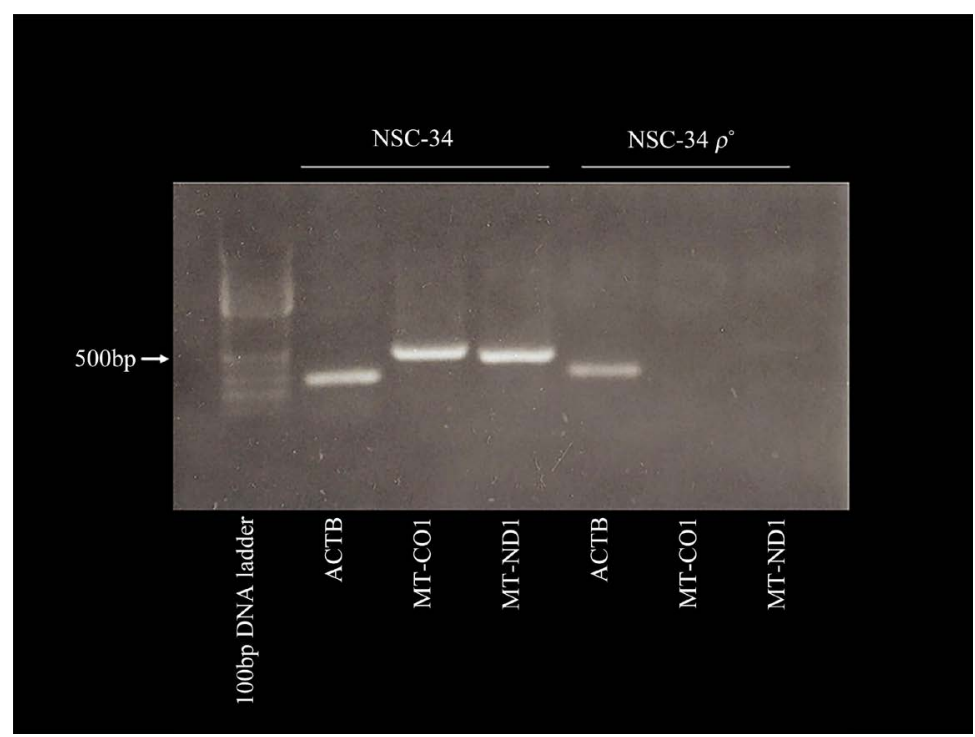

Figure 5. NSC-34 $\rho^{\circ}$ cells lost mitochondrial DNA. No MT-CO1 and MT-ND1 gene is amplified in NSC-34 $\rho^{\circ}$ cells. Genomic gene ACTB is same as parent NSC-34 cells. (Details in Materials and Methods).

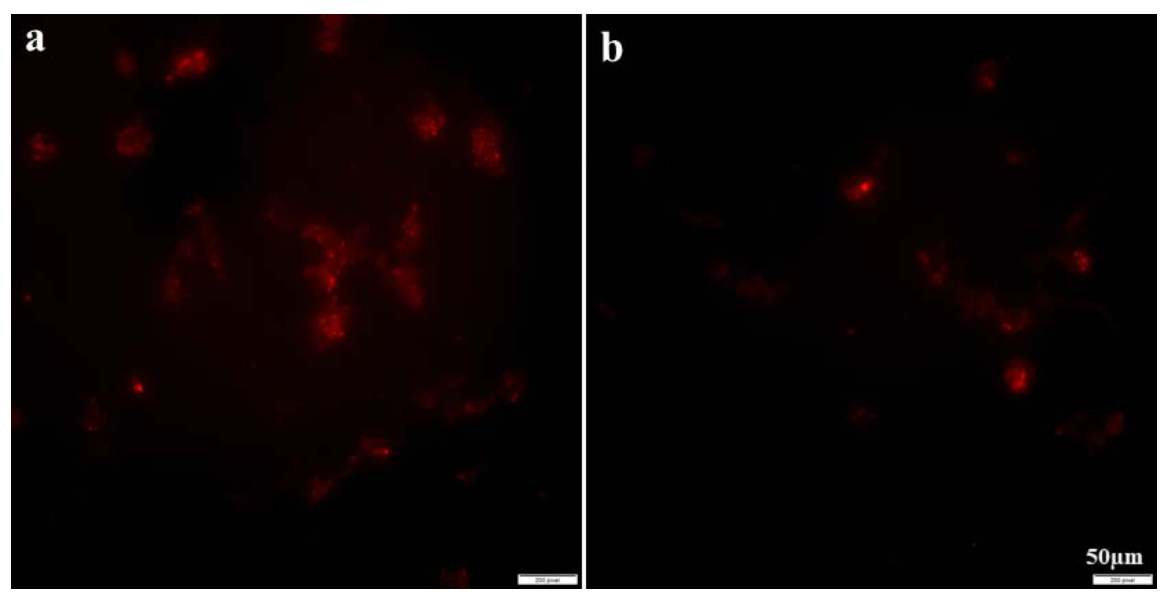

Figure 6. Mitochondria of NSC-34 and primary fibroblast transplant to NSC-34 $\rho^{\circ}$ cells. The mitochondria of NSC-34 and fibroblasts were labelled with MitoTracker red, isolated, and co-cultured with NSC-34 $\rho^{\circ}$ cells for 24 hours. (a) Transplanted with NSC-34 mitochondria; (b) Transplanted with fibroblast mitochondria. 


\subsection{Mitochondria of NSC-34 Replenish mtDNA and Rescue Aerobic Respiration of NSC-34 $\rho^{\circ}$ Cells}

After co-culturing of NSC-34 $\rho^{\circ}$ cells with the isolated NSC-34 mitochondria for 24 hours, PCR shows that MT-CO1 DNA genes are amplified in NSC-34 $\rho^{\circ}$ cells. Moreover, MT-CO1 remains amplification at 3 and 6 days post-mitochondrial transplantation (Figure 7). Amplification of genomic gene ACTB is not changed by mitochondrial transplantation (Figure 7). Levels of gene expression are calculated as the formula: (gene expression of NSC-34 $\rho^{\circ}$ cells $\div$ gene expression of NSC-34 cells) $\times 100 \%$. qPCR shows that NSC34 $\rho^{\circ}$ cells have very low levels of mRNA expression of mitochondrial genes MT-CO1 and MT-ND1 (approximately $10 \%$ of parent NSC-34 cells), but regain mRNA expression to the levels of normal NSC-34 at 3 days post-mitochondrial transplantation (Figure 8). The expression of glycolytic genes, HK2, LDHA and SLC2A1, is upregulated in NSC34 $\rho^{\circ}$ cells. These suggest NSC-34 $\rho^{\circ}$ cells with defective mitochondria increase aerobic glycolysis to produce cell energy ATP. Mitochondrial transplantation downregulates expression of the glycolysis-related genes. The levels of HK2, LDHA and SLC2A1 gene expression return to normal at 3 days post-transplantation of NSC 34 mitochondria (Figure 9). These results suggest that the isolated NSC-34 mitochondria can effectively replenish mitochondrial DNA and rescue aerobic respiration of NSC $34 \rho^{\circ}$ cells. In this study, 10 NSC-34 cells' mitochondria can rescue 1 NSC $34 \rho^{\circ}$ cells with defective mitochondria.

We find that xenogeneic mitochondria from human fibroblasts successfully enter to NSC $34 \rho^{\circ}$ cells (Figure 6(b)). However, we haven't examined the expression of human mitochondrial genes and glycolysis-associated genes in mouse NSC $34 \rho^{\circ}$ cells. More studies remain to be done.

\subsection{Mitochondrial Transplantation in Mouse 4T1 Tumor Model}

At 24 hours post-injection of MitoTracker orange-labelled mitochondria of normal EpH4-Ev cells into tumor mass, orange fluorescence was observed in 4T1 cells (Figure 10). This result suggests that the mitochondria of EpH4-Ev cells successfully transplant into tumor 4T1 cells. At 18 days of experiment, mice were necropsied. Tumor weight in the group that received normal EpH4-Ev mitochondria is not different from tumor weight of the control group $(p>0.05)$. Gross examine shows all mice have lung metastases in both groups. However, lung weight of the group that received mitochondria is less than that of the control group even though the difference is not quite significant $(p=0.06)$ (Table 2). These results suggest that exogeneous normal mitochondria might decrease metastatic burden in lungs.

Subcutaneous injection of mitochondria $\left[5 \times 10^{7}\right.$ mitochondria $(6.6 \mu$ g protein $)$ per mouse] and MRB $(0.2 \mathrm{ml} /$ mouse $)$ didn't cause any side reaction in mice. The doses in mice can be converted to doses of human based on body surface area as the formula: dose of human per kilogram $(\mathrm{kg})$ body weight $=$ mouse dose per $\mathrm{kg} \times 0.081[35,36]$. In this study, mouse averaged weight is $17.3 \mathrm{~g}$. The doses of mice are 0.38 $\mathrm{mg} / \mathrm{kg}$ [0.0066 $\mathrm{mg}$ (mitochondrial protein) $\div 0.0173 \mathrm{~kg}$ mouse weight], or $2.89 \times 10^{9}$ mitochondria $/ \mathrm{kg}(5 \times$ $10^{7}$ mitochondria $\div 0.0173 \mathrm{~kg}$ mouse weight). The equivalent of human doses will be: $0.031 \mathrm{mg} / \mathrm{kg}(0.38$ $\mathrm{mg} / \mathrm{kg}$ in mice $\times 0.081)$ in protein or $2.34 \times 10^{8}$ mitochondria $/ \mathrm{kg}\left(2.89 \times 10^{9}\right.$ in mice $\left.\times 0.081\right)$. These doses can be used as starting dose for clinical trial. Subcutaneous injection of $0.2 \mathrm{ml}$ of MRB is safe for mice. Conversion of the MRB volume to human will be $2-5 \mathrm{ml}$ intramuscular injection per site or $<250 \mathrm{ml}$ intravenous injection [35].

Table 2. Weights of tumor and lungs in 4T1 mammary adenocarcinoma bearing mice treated subcutaneously with mitochondria of EpH4-Ev mammary epithelia.

\begin{tabular}{cccc}
\hline & Control & Transplanted with mitochondria & $\mathrm{p}^{\&}$ \\
\hline Tumor weight $(\mathrm{g})$ & $1.0 \pm 0.27(11)^{\star}$ & $1.1 \pm 0.27(10)$ & 0.48 \\
Lung weight $(\mathrm{g})$ & $0.45 \pm 0.10(11)$ & $0.37 \pm 0.10(10)$ & 0.06 \\
\hline
\end{tabular}

${ }^{\star}$ mean \pm standard deviation (number of mice); \&Student's t-test, less than 0.05 was judged to be of statistical significance. 


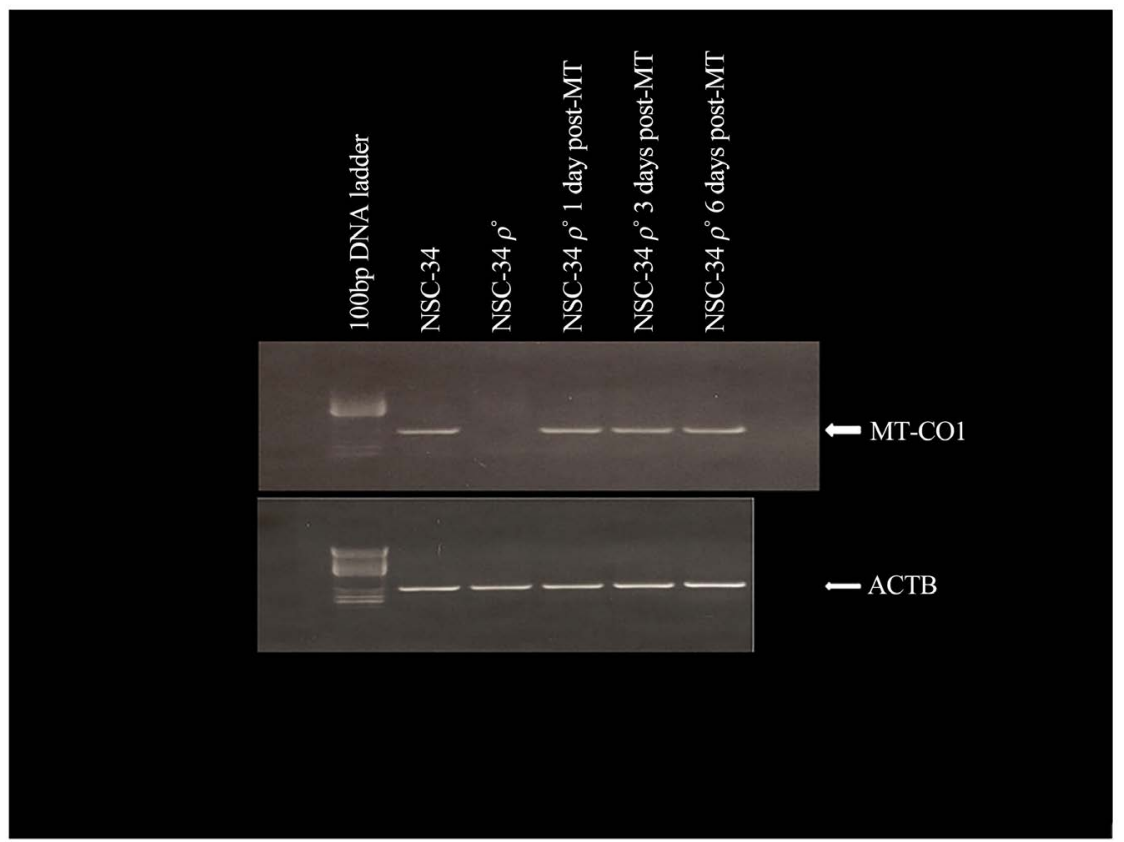

Figure 7. Autologous NSC-34 mitochondria replenish mitochondrial DNA of NSC-34 $\rho^{\circ}$ cells. There are bands of MT-CO1 amplification at 1, 3 and 6 days post-mitochondrial transplantation (MT). (Details in Materials and Methods).

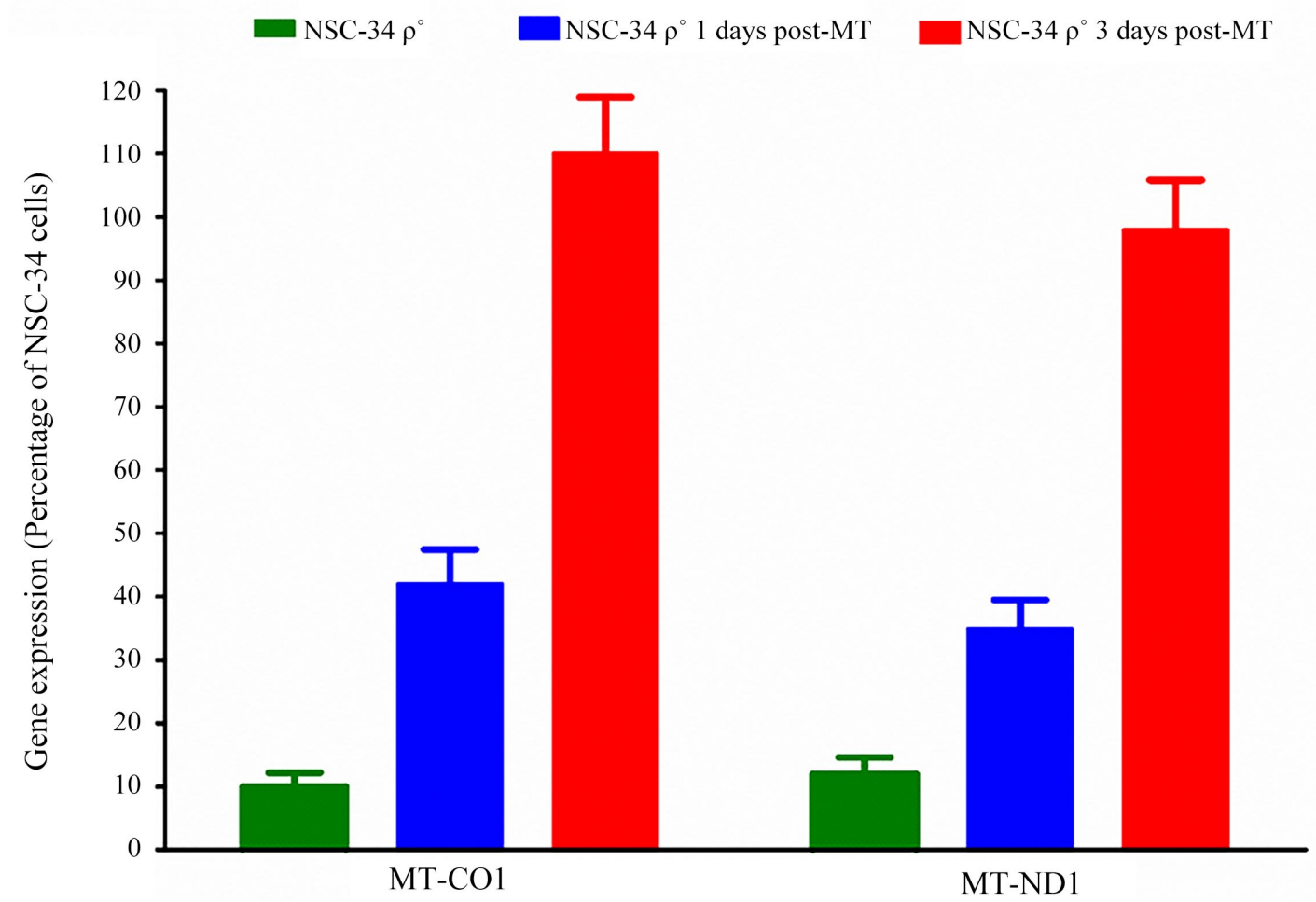

Figure 8. Autologous NSC-34 mitochondria restore MT-CO1 and MT-ND1 gene expression of NSC-34 $\rho^{\circ}$ cells. NSC-34 $\rho^{\circ}$ cells were co-cultured with isolated mitochondria from NSC-34 cells (1 NSC-34 $\rho^{\circ}$ cell + mitochondria from 10 NSC-34 cells). Gene expression is measured by qPCR. (Details in Materials and Methods). 


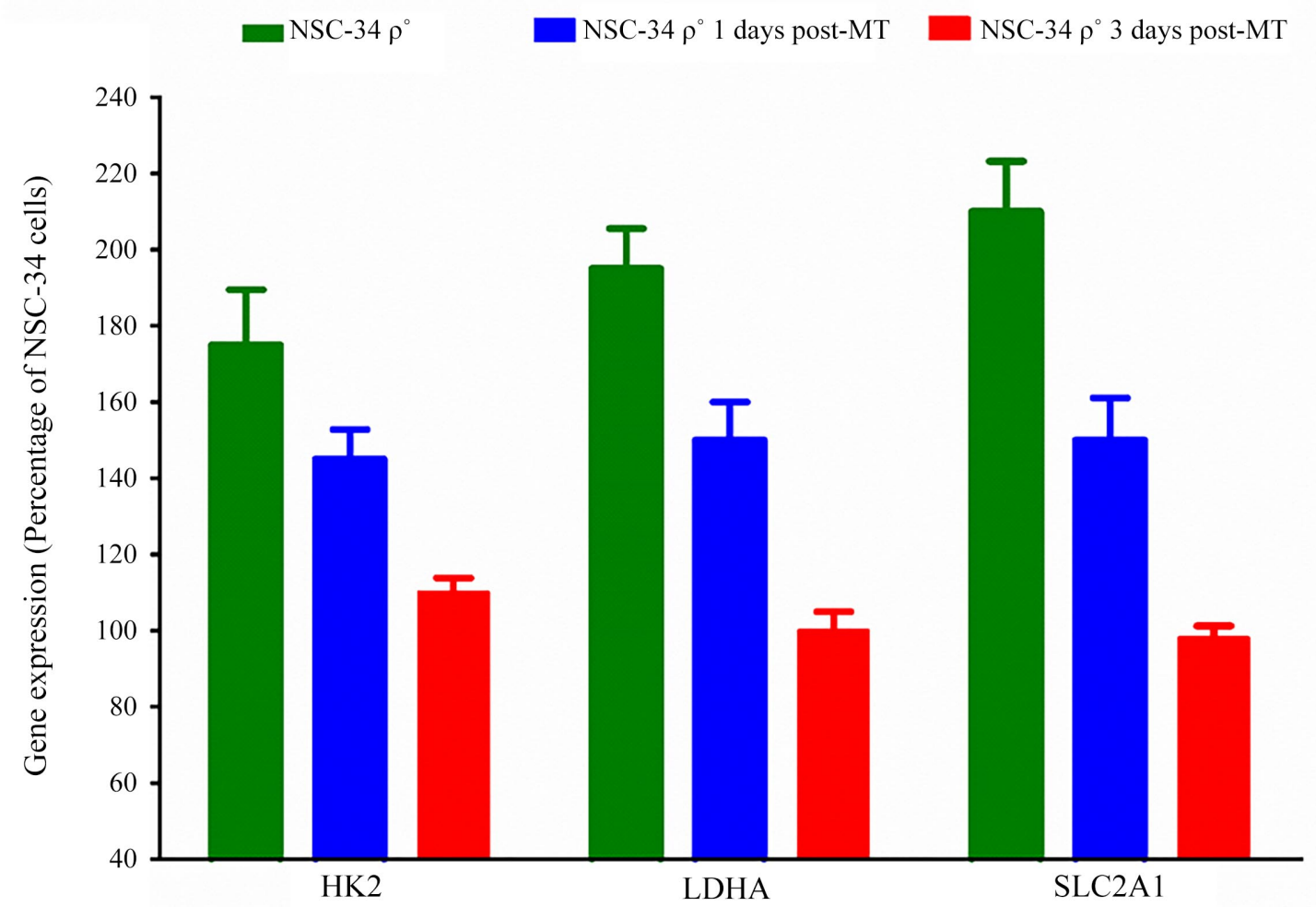

Figure 9. Autologous NSC-34 mitochondria reverse the expression of glycolytic genes of NSC-34 $\rho^{\circ}$ cells. NSC-34 $\rho^{\circ}$ cells were co-cultured with isolated mitochondria from NSC-34 cells (1 NSC-34 $\rho^{\circ}$ cell + mitochondria from 10 NSC-34 cells). Gene expression is measured by qPCR. (Details in Materials and Methods).

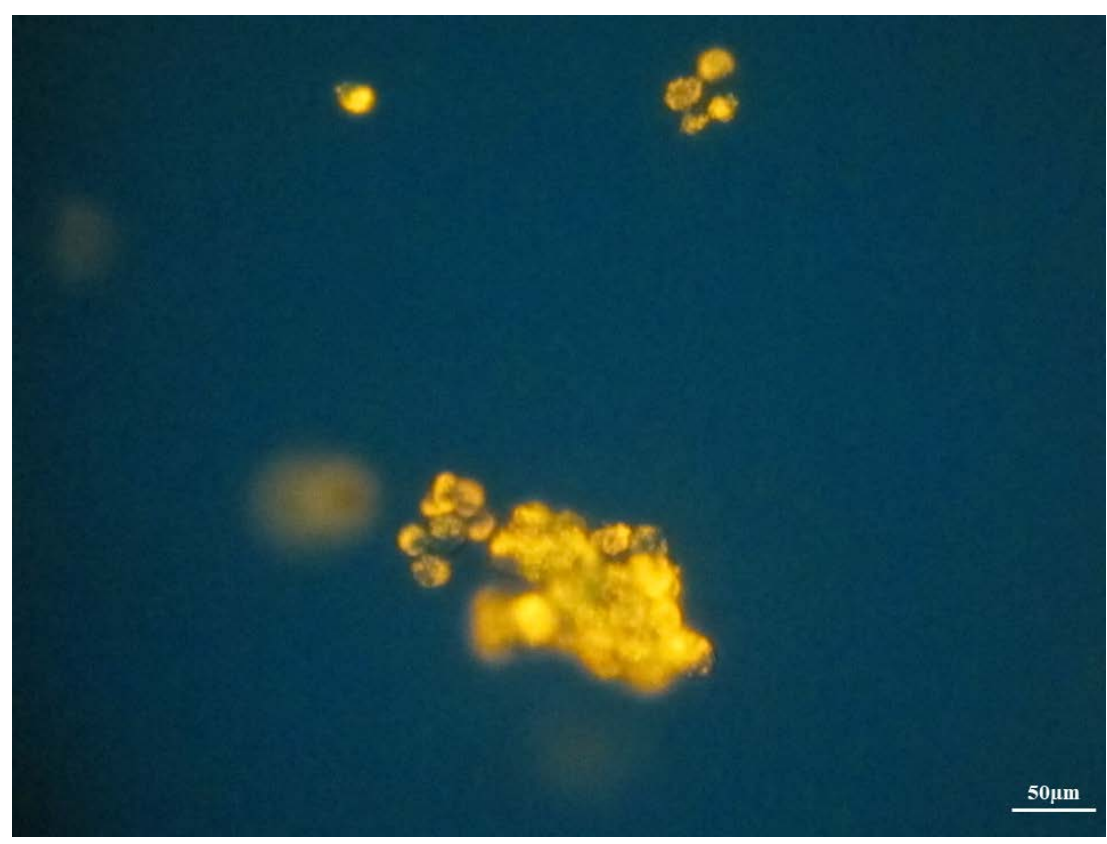

Figure 10. MitoTracker orange-labelled mitochondria of EpH4-Ev successfully transplant to $4 \mathrm{~T} 1$ cells grown in mice. Orange fluorescence was observed in 4T1 cells on tumor smearing slides at 24 hours post-injection of mitochondria. (Details in Materials and Methods). 


\section{DISCUSSION}

The exact etiologies of most neurodegenerative diseases (NDs) remain unclear. Current effective treatment for NDs is limited. NDs are often associated with mitochondrial dysfunction. Thus, targeting to mitochondria-related pathogenesis has increased attention to NDs treatment. Traditional drugs or gene targeting agents are difficult to arrive at specific sub-compartments of mitochondria. Moreover, the diverse nature of mitochondrial mutations among patients makes it impossible to develop one drug to cure one disease. In recent years, mitochondrial transplantation has shed a new light of therapeutic intervention that benefits neuronal survival and regeneration for neurodegenerative diseases, stroke, and CNS injury. Exogenous healthy mitochondria transplant to defective neurons and promote neuronal viability, activity and neurite re-growth [37-39]. In this study, mtDNA-depleted motor neuron NSC-34 (NSC-34 $\rho^{\circ}$ ) cells grow much slower than parent NSC-34 cells. NSC-34 $\rho^{\circ}$ cells increase aerobic glycolysis, a less efficient pathway to make ATP than OXPHOS (Figure 9). NSC-34 $\rho^{\circ}$ cells can be a mitochondrial defective model of motor neuron. Motor neurons in brain and spinal cord have defects and stop working properly in ALS patients. NSC-34 $\rho^{\circ}$ cells are a useful tool for mitochondrial pathogenesis research of ALS. Transplantation of NSC-34 mitochondria replenishes mtDNA of NSC-34 $\rho^{\circ}$ cells confirmed by PCR (Figure 7, Figure 8). After mitochondrial transplantation, the expression of glycolytic genes HK2, LDHA and SLC2A1 are decreased at 1 day and to the normal levels of NSC-34 cells at 3 days (Figure 9). Dong LF et al reported that $\mathrm{B} 16 \rho^{\circ}$ mouse melanoma cells acquired mtDNA by transfer of whole mitochondria from the host animal, leading to normalization of mitochondrial respiration [40]. Katrangi E et al published that xenogeneic transfer of murine mitochondria into human $\rho^{\circ}$ cells could functionally restore respiration in cells lacking mtDNA [41]. Therefore, the feasibility of using cellular internalization of isolated exogenous mitochondria is a potential tool for studying mitochondrial genetics and biotherapy for NDs and other mitochondria-related diseases.

Chang et al used P12 cells as a donor of mitochondria to treat Parkinson's disease rat model [29]. PC12 is a cell line derived from a pheochromocytoma of the rat adrenal medulla, that has an embryonic origin from the neural crest that has a mixture of neuroblastic cell and eosinophilic cells [42]. Shi X et al intravenously injected human hepatoma's mitochondria to experimental Parkinson's disease (PD) model mice induced by respiratory chain inhibitor MPTP and found that the mitochondrial transplantation prevented experimental PD progress by increasing the activity of electron transport chain, decreasing reactive oxygen species, and preventing cell apoptosis and necrosis [39]. By using tumor cells as mitochondrial donor for mitochondrial transplantation, the safety and ethics are problematic in future human study. A registered study for mitochondrial transplantation on ClinicalTrials.gov "Transplantation of Autologously Derived Mitochondria Following Ischemia"

(https://clinicaltrials.gov/ct2/show/NCT02851758) described that human autologous mitochondria of skeletal muscle will be injected to ischemic cardiac muscle. Similar to cardiac muscle, skeletal muscle is striated. In addition, skeletal muscle is plentiful in human. Thus skeletal muscle is reasonable mitochondrial donor for mitochondrial transplantation following cardiac ischemia. However, it is difficult to find allogeneic or autologous neurons as mitochondrial donor because nerve systems are limited in self-repair and regeneration. We selected human fibroblasts as mitochondrial donors in mitochondrial transplantation for human NDs for following reasons: 1) Fibroblasts have abundant tissue sources and are capable of regeneration in human. 2) Fibroblasts often exchange mitochondria with other cells including neurons [43, 44]. 3) Fibroblasts share many characteristics with mesenchymal stromal/stem cells (MSCs) $[45,46]$. MSCs cellular therapy has been used for widespread trials for inflammatory, immune-mediated, and degenerative diseases, attributed to their immunomodulatory, immunosuppressive and regenerative potentials [47]. and 4) Human fibroblasts can be induced to functional neurons [48]. We find human primary fibroblasts are easily isolated and expanded fast. Mitochondria are dynamic cell organelles with continuous fission and fusion. However, cells have relatively stable number of mitochondria in normal physiological situation. Number of mitochondria in a cell can vary widely by organ, tissue, and cell type. For instance, red blood cells have no mitochondria, whereas liver cells can have more than 2000 [49]. The 
human fibroblasts have abundant mitochondria (averaged 337 mitochondria per fibroblasts). We find that human fibroblasts transfer mitochondria to human mammary adenocarcinoma cell line MCF-7 (Figure 4). Mitochondrial transfer between fibroblasts and cancer might benefit cancer growth [50]. However, fibroblast mitochondrial transfer with normal cells may rescue aerobic respiration of injured cells and benefit tissue repair and regeneration $[43,44]$. Our protocol of mitochondrial isolation yields to $42.4 \%$ of intracellular mitochondria of fibroblasts. Fibroblast number can be used as fast method to estimate mitochondrial number during mitochondrial transplantation trial because isolated mitochondria's short life (less than a few hours on ice). From $1 \times 10^{7}$ fibroblasts, final number of the isolated mitochondria is $1.43 \times 10^{9}\left(1 \times 10^{7} \times 337 \times 42.4 \%=1.43 \times 10^{9}\right)$. Mitochondrial protein content is an alternative way to determine mitochondrial number, but the procedure often takes a few hours. Thus, mitochondria protein content is less practical than cell number to estimate mitochondrial number in mitochondrial transplantation trial. The isolated mitochondria maintain membrane potential gradient. Mitochondrial membrane potential is generated by proton pump (Complex I, III and IV) and serves as an intermediate form of energy storage which is used by ATP synthase to make ATP. Membrane potential is also a factor determining viability of mitochondria and a driving force for transport of charged compounds some of which are essential for mitochondrial viability. Loss of mitochondrial membrane potential will induce mitophagy to eliminate the damaged mitochondria [51,52]. Thus, mitochondrial membrane potential is a marker for viability of isolated mitochondria. Mitochondrial membrane potential can be determined by mitochondrial fluorescent probes such as JC-1, MitoTracker dyes, Tetramethylrhodamine ethyl (TMRE) or methyl (TMRM) ester. Isolated mitochondrial viability can be rapidly and easily determined by using the mitochondrial fluorescent probes $[24,25,33,51]$. The isolated fibroblast's mitochondria successfully transplant to defective mouse motor neuron NSC-34 $\rho^{\circ}$ cells (Figure 6(b)). In agreement with Chang JC group's report [29], our result shows xenogeneic mitochondria can transplant to recipient cells from different species. Overall, human primary fibroblasts are optimal mitochondrial donor for mitochondrial transplantation for NDs. However, more studies such as gene expression of fibroblast mitochondria in recipient cells remain to be done in near future.

Allogeneic tissue donors are required HLA typing match. The human leukocyte antigen (HLA) system or complex is a group of related proteins that are encoded by the major histocompatibility complex (MHC) gene complex in humans. HLA I molecules are one of two primary classes of MHC molecules on cell surface of all nucleated cells, and include HLA-A, HLA-B, and HLA-C. HLA II is found only on professional antigen-presenting cells such as dendritic cells and B cells. The immune system uses the HLAs to differentiate self cells from non-self cells $[53,54]$. Fibroblasts may express low level of HLA I antigen because of similarity of fibroblasts and MSCs [44, 45, 55]. Our results show primary fibroblasts express HLA-I antigen on cell surface, but the isolated mitochondria from fibroblasts don't express any HLA-I antigen (Figure 3). These results suggest allogeneic mitochondria exhibit low or no immunogenicity and need no HLA tying match in mitochondrial transplantation. It is possible that fibroblast mitochondria become a "Off-the-Shelf" product for biotherapy.

Mitochondrial transplantation may have potential for cancer therapy. We previously reported mitochondrial isolated from normal mammary epithelial MCF-12A transplanted to human breast carcinoma cell lines, downregulated gene expression of glycolytic enzymes and increased cancer drug sensitivity $[21,28]$. In the present study, we find normal mitochondria successfully enter the tumor 4T1 cells in mice at 24 hours after mitochondrial injection in tumor mass (Figure 10). In other groups of mice, normal mitochondria (mitochondria from $10 \mathrm{EpH} 4-\mathrm{Ev}$ cells +1 tumor $4 \mathrm{~T} 1$ cell) fail to inhibit tumor growth. Normal mitochondria decrease lung weight but the different is not quite significant $(\mathrm{p}=0.06)$, compared to the control group. Inhibitory effect of normal mitochondria on tumor cells may depend on dosage of mitochondria. Further study such as increasing mitochondria remains to be done. We find subcutaneous injection of $0.2 \mathrm{ml}$ mitochondria and MRB is safe for mice. The mitochondria number and MRB volume in mice can be converted to human dose as an estimation of starting dose for clinical trial $[35,36]$. 


\section{CONCLUSION}

Mitochondrial transplantation could replenish mtDNA and rescue aerobic respiration of cells with defective mitochondria. Human primary fibroblasts are a potential mitochondrial donor for mitochondrial transplantation study in human neurodegenerative diseases.

\section{ACKNOWLEDGEMENTS}

Financial support from The Sallie A. Burdine Breast Foundation, Baton Rouge, Louisiana, USA.

\section{CONFLICTS OF INTEREST}

The authors declare no conflicts of interest regarding the publication of this paper.

\section{REFERENCES}

1. Murphy, E., Ardehali, H., Balaban, R.S., DiLisa, F. and DornII, G.W. (2016) Mitochondrial Function, Biology, and Role in Disease. Circulation Research, 118, 1960-1991. https://doi.org/10.1161/RES.0000000000000104

2. Braymer, J.J. and Lill, R. (2017) Iron-Sulfur Cluster Biogenesis and Trafficking in Mitochondria. The Journal of Biological Chemistry, 292, 12754-12763. https://doi.org/10.1074/jbc.R117.787101

3. Herst, P.M., Rowe, M.R., Carson, G.M. and Berridge, M.V. (2017) Functional Mitochondria in Health and Disease. Frontiers in Endocrinology, 9, 1-16. https://doi.org/10.3389/fendo.2017.00296

4. Westermann, B. (2020) Mitochondrial Fusion and Fission in Cell Life and Death. Nature Reviews Molecular Cell Biology, 11, 872-884. https://doi.org/10.1038/nrm3013

5. Twig, G., Hyde, B. and Shirihai, O.S. (2008) Mitochondrial Fusion, Fission and Autophagy as a Quality Control Axis: The Bioenergetic View. Biochimica et Biophysica Acta (BBA) Bioenergetics, 1777, 1092-1097. https://doi.org/10.1016/j.bbabio.2008.05.001

6. Spees, J.L., Olson, S.D., Whitney, M.J. and Prockop, D.J. (2006) Mitochondrial Transfer between Cells Can Rescue Aerobic Respiration. Proceedings of the National Academy of Sciences of the United States of America, 103, 1283-1288. https://doi.org/10.1073/pnas.0510511103

7. Pasquier, J., Guerrouahen, B.S. and Thawadi, H.A. (2013) Preferential Transfer of Mitochondria from Endothelial to Cancer Cells through Tunneling Nanotubes Modulates Chemoresistance. Journal of Translational Medicine, 11, 94. https://doi.org/10.1186/1479-5876-11-94

8. Newell, C., Sabouny, R., Hittel, D.S. and Shutt, T.E. (2018) Mesenchymal Stem Cells Shift Mitochondrial Dynamics and Enhance Oxidative Phosphorylation in Recipient Cells. Frontiers in Physiology, 9, 1572. https://doi.org/10.3389/fphys.2018.01572

9. Boukelmoune, N., Chiu, G.S., Kavelaars, A. and Heijnen, C.J. (2018) Mitochondrial Transfer from Mesenchymal Stem Cells to Neural Stem Cells Protects against the Neurotoxic Effects of Cisplatin. Acta Neuropathologica Communications, 6, 139. https://doi.org/10.1186/s40478-018-0644-8

10. Smith, E.F., Shaw, P.J. and De Vos, K.J. (2019) The Role of Mitochondria in Amyotrophic Lateral Sclerosis. Neuroscience Letters, 710, Article ID: 132933. https://doi.org/10.1016/j.neulet.2017.06.052

11. Federico, A., Cardaioli, E., Pozzo, P.D., Formichi, P., Gallus, G.N. and Radi, E. (2012) Mitochondria, Oxidative Stress and Neurodegeneration. Journal of the Neurological Sciences, 322, 254-262. https://doi.org/10.1016/j.jns.2012.05.030

12. Moreira, P.I., Zhu, X., Wang, X., Lee, H., Nunomura, A., Petersen, R.B., Perry, G. and Smith, M.A. (2010) Mitochondria: A Therapeutic Target in Neurodegeneration. Biochimica et Biophysica Acta, 1802, 212-220. https://doi.org/10.1016/j.bbadis.2009.10.007 
13. Perez Ortiz, J.M. and Swerdlow, R.H. (2019) Mitochondrial Dysfunction in Alzheimer's Disease: Role in Pathogenesis and Novel Therapeutic Opportunities. British Journal of Pharmacology, 176, 3489-3507. https://doi.org/10.1111/bph.14585

14. Moreira, P.I., Cristina Carvalho, C., Zhu, X., Smith, M.A. and Perry, G. (2010) Mitochondrial Dysfunction Is a Trigger of Alzheimer's Disease Pathophysiology. Biochimica et Biophysica Acta (BBA) Molecular Basis of Disease, 1802, 2-10. https://doi.org/10.1016/j.bbadis.2009.10.006

15. Ndayisaba, A., Kaindlstorfer, C. and Wenning, G.K. (2019) Iron in Neurodegeneration-Cause or Consequence? Frontiers in Neuroscience, 13, 180. https://doi.org/10.3389/fnins.2019.00180

16. Müller, M., Ahumada-Castro, U., Sanhueza, M., Gonzalez-Billault, C., Court, F.A. and Cárdenas, C. (2018) Mitochondria and Calcium Regulation as Basis of Neurodegeneration Associated with Aging. Frontiers in Neuroscience, 12, 470. https://doi.org/10.3389/fnins.2018.00470

17. Deng, J., Yang, M., Chen, Y. and Chen, X. (2015) FUS Interacts with HSP60 to Promote Mitochondrial Damage. PLOS Genetics, 11, e1005357. https://doi.org/10.1371/journal.pgen.1005357

18. Siasos, G., Tsigkou, V., Kosmopoulos, M., Theodosiadis, D., Simantiris, S. and Tagkou, N.M. (2018) Mitochondria and Cardiovascular Diseases-from Pathophysiology to Treatment. Annals of Translational Medicine, 6, 256. https://doi.org/10.21037/atm.2018.06.21

19. Warburg, O. (1956) On the Origin of Cancer Cells. Science, 123, 309-314. https://doi.org/10.1126/science.123.3191.309

20. Carew, J.S. and Huang, P. (2002) Mitochondrial Defects in Cancer. Molecular Cancer, 1, 9. https://doi.org/10.1186/1476-4598-1-9

21. Elliott, R.L., Jiang, X.P. and Head, J.F. (2012) Mitochondria Organelle Transplantation: Introduction of Normal Epithelial Mitochondria into Human Cancer Cells Inhibits Proliferation and Increases Drug Sensitivity. Breast Cancer Research and Treatment, 136, 347-354. https://doi.org/10.1007/s10549-012-2283-2

22. Gill, K.S., Fernandes, P., O’Donovan, T.R., McKenna, S.L., Doddakula, K.K., Power, D.G., Soden, D.M. and Forde, P.F. (2016) Glycolysis Inhibition as a Cancer Treatment and Its Role in an Anti-Tumour Immune Response. Biochimica et Biophysica Acta, 1866, 87-105. https://doi.org/10.1016/j.bbcan.2016.06.005

23. Cantelmo, A.R., Conradi, L.C., Brajic, A., Goveia, J., Kalucka, J. and Pircher, A. (2016) Inhibition of the Glycolytic Activator PFKFB3 in Endothelium Induces Tumor Vessel Normalization, Impairs Metastasis, and Improves Chemotherapy. Cancer Cell, 30, 968-985. https://doi.org/10.1016/j.ccell.2016.10.006

24. Pacak, C.A., Preble, J.M., Kondo, H., Seibel, P., Levitsky, S., del Nido, P.J., Cowan, D.B. and McCully, J.D. (2015) Actin-Dependent Mitochondrial Internalization in Cardiomyocytes: Evidence for Rescue of Mitochondrial Function. Biology Open, 4, 622-626. https://doi.org/10.1242/bio.201511478

25. McCully, J.D., Cowan, D.B., Pacak, C.A., Toumpoulis, I.K., Dayalan, H. and Levitsky, S. (2009) Injection of Isolated Mitochondria during Early Reperfusion for Cardioprotection. American Journal of Physiology: Heart and Circulatory Physiology, 296, H94-H105. https://doi.org/10.1152/ajpheart.00567.2008

26. Cowan, D.B., Yao, R., Akurathi, V., Snay, E.R. and Thedsanamoorthy, J.K. (2016) Intracoronary Delivery of Mitochondria to the Ischemic Heart for Cardioprotection. PLOS ONE, 11, e0160889.

https://doi.org/10.1371/journal.pone.0160889

27. Gollihue, J.L., Patel, S.P., Eldahan, K.C., Cox, D.H., Donahue, R.R., Taylor, B.K., Sullivan, P.G. and Rabchevsky, A.G. (2018) Effects of Mitochondrial Transplantation on Bioenergetics, Cellular Incorporation, and Functional Recovery after Spinal Cord Injury. Journal of Neurotrauma, 35, 1800-1818. https://doi.org/10.1089/neu.2017.5605

28. Jiang, X.P., Elliott, R.L. and Head, J.F. (2015) Exogenous Normal Mammary Epithelial Mitochondria Suppress 
Glycolytic Metabolism and Glucose Uptake of Human Breast Cancer Cells. Breast Cancer Research and Treatment, 153, 519-529. https://doi.org/10.1007/s10549-015-3583-0

29. Chang, J.C., Wu, S.L., Liu, K.H. and Chen, Y.H. (2016) Allogeneic/Xenogeneic Transplantation of Peptide-Labeled Mitochondria in Parkinson's Disease: Restoration of Mitochondria Functions and Attenuation of 6-Hydroxydopamine-Induced Neurotoxicity. Translational Research, 170, 40-56.e3.

https://doi.org/10.1016/j.trsl.2015.12.003

30. Preble, J.M., Pacak, C.A., Kondo, H., MacKay, A.A., Cowan, D.B. and McCully, J.D. (2014) Rapid Isolation and Purification of Mitochondria for Transplantation by Tissue Dissociation and Differential Filtration. Journal of Visualized Experiments, 91, 51682-51688. https://doi.org/10.3791/51682

31. Corcelli, A., Saponetti, M.S., Zaccagnino, P., Lopalco, P., Mastrodonato, M., Liquori, G.E. and Lorusso, M. (2010) Mitochondria Isolated in Nearly Isotonic KCl Buffer: Focus on Cardiolipin and Organelle Morphology. Biochimica et Biophysica Acta, 1798, 681-687. https://doi.org/10.1016/j.bbamem.2010.01.005

32. Wollenman, L.C., Vander Ploeg, M.R., Miller, M.L., Zhang, Y. and Bazil, J.N. (2017) The Effect of Respiration Buffer Composition on Mitochondrial Metabolism and Function. PLOS ONE, 12, e0187523. https://doi.org/10.1371/journal.pone.0187523

33. Preble, J.M., Kondo, H., Levitsky, S. and McCully, J.D. (2014) Quality Control Parameters for Mitochondria Transplant in Cardiac Tissue. JSM Biochemistry \& Molecular Biology, 2, 1008-1014.

34. Hayakawa, T., Noda, M., Yasuda, K., Yorifuji, H. and Taniguchi, S. (1998) Ethidium Bromide-Induced Inhibition of Mitochondrial Gene Transcription Suppresses Glucose-Stimulated Insulin Release in the Mouse Pancreatic Beta-Cell Line betaHC9. Journal of Biological Chemistry, 273, 20300-20307. https://doi.org/10.1074/jbc.273.32.20300

35. Nair, A.B. and Jacob, S.A. (2016) Simple Practice Guide for Dose Conversion between Animal and Human. Journal of Basic and Clinical Pharmacy, 7, 27-31. https://doi.org/10.4103/0976-0105.177703

36. USFDA (2005) Guidance for Industry: Estimating the Maximum Safe Starting Dose in Adult Healthy Volunteer. US Food and Drug Administration, Rockville.

37. Chang, C.Y., Liang, M.Z. and Chen, L. (2019) Current Progress of Mitochondrial Transplantation That Promotes Neuronal Regeneration. Translational Neurodegeneration, 8, 17.

https://doi.org/10.1186/s40035-019-0158-8

38. Chien, L., Liang, M.Z., Chang, C.Y., Wang, C. and Chen, L. (2018) Mitochondrial Therapy Promotes Regeneration of Injured Hippocampal Neurons. Biochimica et Biophysica Acta, 1864, 3001-3012. https://doi.org/10.1016/j.bbadis.2018.06.012

39. Shi, X., Zhao, M., Fu, C. and Fu, A. (2017) Intravenous Administration of Mitochondria for Treating Experimental Parkinson's Disease. Mitochondrion, 34, 91-100. https://doi.org/10.1016/j.mito.2017.02.005

40. Dong, L.F., Kovarova, J., Bajzikova, M. and Bezawork-Geleta, A. (2017) Horizontal Transfer of Whole Mitochondria Restores Tumorigenic Potential in Mitochondrial DNA-Deficient Cancer Cells. Elife, 6, e22187. https://doi.org/10.7554/eLife.22187.012

41. Katrangi, E., D’Souza, G., Boddapati, S.V., Kulawiec, M., Singh, K.K., Bigger, B. and Weissig, V. (2007) Xenogenic Transfer of Isolated Murine Mitochondria into Human $\rho^{0}$ Cells Can Improve Respiratory Function. Rejuvenation Research, 10, 561-570. https://doi.org/10.1089/rej.2007.0575

42. Greene, L.A. and Tischler, A.S. (1976) Establishment of a Noradrenergic Clonal Line of Rat Adrenal Pheochromocytoma Cells Which Respond to Nerve Growth Factor. Proceedings of the National Academy of Sciences of the United States of America, 73, 2424-2428. https://doi.org/10.1073/pnas.73.7.2424

43. Gao, L., Zhang, Z., Lu, J. and Pei, G. (2019) Mitochondria Are Dynamically Transferring between Human Neural Cells and Alexander Disease-Associated GFAP Mutations Impair the Astrocytic Transfer. Frontiers in 
Cellular Neuroscience, 13, 316. https://doi.org/10.3389/fncel.2019.00316

44. Paliwal, S., Chaudhuri, R., Agrawa, A. and Mohanty, S. (2018) Regenerative Abilities of Mesenchymal Stem Cells through Mitochondrial Transfer. Journal of Biomedical Science, 25, 31.

https://doi.org/10.1186/s12929-018-0429-1

45. Denu, R.A., Nemcek, S., Bloom, D.D., Goodrich, A.D., Kim, J., Mosher, D.F. and Hematti, P. (2016) Fibroblasts and Mesenchymal Stromal/Stem Cells Are Phenotypically Indistinguishable. Acta Haematologica, 136, 85-97. https://doi.org/10.1159/000445096

46. Soundararajan, M. and Kannan, S. (2018) Fibroblasts and Mesenchymal Stem Cells: Two Sides of the Same Coin? Journal of Cellular Physiology, 233, 9099-9109. https://doi.org/10.1002/jcp.26860

47. Saeedi, P., Halabian, R. and Fooladi, A.A. (2019) A Revealing Review of Mesenchymal Stem Cells Therapy, Clinical Perspectives and Modification Strategies. Stem Cell Investigation, 6, 34.

https://doi.org/10.21037/sci.2019.08.11

48. Kim, Y., Zheng, X., Ansari, Z. and Bunnell, M.C. (2018) Mitochondrial Aging Defects Emerge in Directly Reprogrammed Human Neurons Due to Their Metabolic Profile. Cell Reports, 23, 2550-2558. https://doi.org/10.1016/j.celrep.2018.04.105

49. Voet, D., Voet, J.G. and Pratt, C.W. (2006) Fundamentals of Biochemistry. 2nd Edition, John Wiley and Sons, Inc., Hoboken, 547, 556.

50. Ippolito, L., Morandi, A., Taddei, M.L., Parri, M., Comito, G. and Iscaro, A. (2019) Cancer-Associated Fibroblasts Promote Prostate Cancer Malignancy via Metabolic Rewiring and Mitochondrial Transfer. Oncogene, 38, 5339-5355. https://doi.org/10.1038/s41388-019-0805-7

51. Zorova, L.D., Popkov, V.A., Plotnikov, E.Y., Silachev, D.N. and Pevzner, I.B. (2018) Mitochondrial Membrane Potential. Analytical Biochemistry, 552, 50-59. https://doi.org/10.1016/j.ab.2017.07.009

52. Ashrafi, G. and Schwarz, T.L. (2013) The Pathways of Mitophagy for Quality Control and Clearance of Mitochondria. Cell Death \& Differentiation, 20, 31-42. https://doi.org/10.1038/cdd.2012.81

53. Parham, P. and Ohta, T. (1996) Population Biology of Antigen Presentation by MHC Class I Molecules. Science, 272, 67-74. https://doi.org/10.1126/science.272.5258.67

54. Choo, S.Y. (2008) The HLA System: Genetics, Immunology, Clinical Testing, and Clinical Implications. Yonsei Medical Journal, 48, 11-23. https://doi.org/10.3349/ymj.2007.48.1.11

55. Wang, Y., Huang, J., Gong, L., Yu, D., An, C., Bunpetch, V. and Dai, J. (2019) The Plasticity of Mesenchymal Stem Cells in Regulating Surface HLA-I. iScience, 15, 66-78. https://doi.org/10.1016/j.isci.2019.04.011 